\title{
Resistências ao trabalho precário por meio de relações solidárias: quatro casos do Brasil
}

Resistance to precarious work through solidarity relations: four cases from Brazil

\author{
Leny Sato \\ Universidade de São Paulo \\ Cris Fernández Andrada \\ Pontifícia Universidade Católica de São Paulo
}

\author{
Egeu Gómez Esteves \\ Universidade Federal de São Paulo \\ Juliana da Silva Nóbrega \\ Universidade Federal de Rondônia
}

\begin{abstract}
Resumo
0 artigo apoia-se em quatro investigações empíricas realizadas no marco teórico da Psicologia Social do Trabalho. No Brasil, a desigualdade antiga e persistente, somada à substituição de postos de trabalho regulados por novas formas de trabalho precário, promove implicações à saúde e à subjetividade de trabalhadores que têm que lidar com diversos riscos frente à manutenção da vida. Com objetivo de discutir modos pelos quais trabalhadores enfrentam este processo, apresentamos casos que expressam formas coletivas de resistências. A metanálise evidenciou que segmentos pobres da população constroem relações de trabalho e de vida social baseadas na cooperação, ajuda mútua e vínculos comunitários, que representam formas de resistência à precarização do trabalho. Embora cada caso tenha origens, propósitos e alcances distintos, a solidariedade neles presente evidencia a possibilidade de construção de relações sociais capazes de produzir e sustentar outras economias e subjetividades, a depender de cada circunstância e intencionalidade.
\end{abstract}

Palavras-chave: Relações solidárias; Trabalho precário; Psicologia social do trabalho; Brasil

\begin{abstract}
This paper is based on four empirical researches conducted within the theoretical framework of the Social Psychology of Work. In Brazil, the old and persistent inequality, added to the replacement of regulated jobs by new forms of precarious work, promotes implications for the health and subjectivity of workers who have to deal with various risks in order to maintain life. In order to discuss ways in which workers face this process, we present cases that express collective forms of resistance. The meta-analysis showed that poor segments of the population build work relations and social life based on cooperation, mutual help, and community ties that represent forms of resistance to the labor precarization. Although each case has different origins, purposes and scope, the solidarity present in them highlights the possibility of building social relations capable of producing and sustaining other economies and subjectivities, depending on each circumstance and intentionality.
\end{abstract}

Keywords: Solidarity relations; Precarious work; Social psychology of work; Brazil 


\section{INTRODUÇÃO}

Nosso objetivo é discutir as potencialidades de modos pelos quais trabalhadores resistem e enfrentam a precarização crescente do trabalho. Iniciaremos discutindo o contexto laboral brasileiro, complexo e desigual, próprio de uma região onde a sociedade salarial não se efetivou de forma majoritária. Contudo, antes é necessário afirmar que a presença de formas não-capitalistas de trabalho, produção, comercialização e crédito nos países subdesenvolvidos é algo antigo e persistente e que, frequentemente, tais formas constituem as únicas possibilidades de sobrevivência para parcelas da população que vivem com pouca ou nenhuma proteção laboral. Se as formas tradicionais aparecem como "informais" e mantêm-se precárias, devemos indagar se isso se deve à características intrínsecas delas ou à maneira como foram invisibilizadas e negadas pelas elites e seus legisladores.

Ao escrever sobre a feira livre na vida da metrópole de São Paulo (Brasil), Leny Sato (2012) recupera um registro da persistência de formas tradicionais do trabalho na vida atual de cidades modernas:

Está provado, meus amigos, e ninguém mais discute que a feira livre é um negócio de características medievais, anti-higiênico, que inunda as ruas com toneladas de lixo, espalha mau cheiro e perturba o sono de pacatos e honestos cidadãos na faina de armar suas barracas pela madrugada".

0 público aplaudiu-o freneticamente. Estimulado pelo incentivo da platéia, o negociante levantou mais a voz e lançou a sentença definitiva: "Não se admite mais, senhores, a presença de feiras livres em pleno século XVIII.

"Engano seu" - bradou um feirante misturado à multidão. "O que não se admite mais é a presença do século XVIII nas feiras livres". (Carlos Eduardo Novaes, Jornal do Brasil, 22 jul. 1973, como citado em Sato, 2012, p. 54)

A mesma persistência teimosa da feira livre pode ser estendida aos camelôs, comércio popular das ruas das cidades dos países subdesenvolvidos. Conhecidas no Brasil colonial como quitandas, sua presença na cidade de São Paulo foi registrada por Saint-Hilaire entre 1816 e 1822 (Sato, 2012). Da kitânda angolana ao potiron tupi, da coleta de víveres à pesca artesanal e às trocas de sementes entre camponeses, o Brasil apresenta uma miríade de formações sociais e econômicas ancestrais, por vezes imersas nas tradições indígenas ou quilombolas, ora autóctones ora trazidas pelas culturas que aqui aportaram em cinco séculos de globalização e de fluxos migratórios.

Ancestrais sim, mas não residuais. Estas antigas maneiras de produzir, trocar e viver estão na origem daquilo que Milton Santos chamou de circuito inferior da economia urbana e que José Luis Coraggio denominou de economia popular. 
Enquanto as atividades do circuito superior (empresarial) visam sobretudo a acumulação de capital, as atividades do circuito inferior (popular) visam a "reproducción ampliada de la vida biológica y cultural de sus miembros" (Coraggio, 1993, p. 11) pois, "trata-se, antes de tudo, de sobreviver e de assegurar a vida cotidiana da família” (Santos, 1979/2004, p. 46). A integração entre os circuitos inferior e superior, contudo, coloca as formas populares numa posição dependente e subordinada em relação às empresariais, o que, conforme Francisco de Oliveira (2013), faz com que o Brasil pareça um ornitorrinco, um animal híbrido e desengonçado.

No Brasil e demais países da América Latina o subdesenvolvimento se alicerça em formas simultâneas de dominação, desde o passado colonial. A exploração das classes populares acontece em atividades necessárias à reprodução da vida social, sempre partindo das desigualdades persistentes, acumuladas anteriormente (Tilly, 2000). É o que ocorre na precarização das relações de trabalho, com agravamento da incerteza, da insegurança e da vulnerabilidade (Julián, 2017). Em outras palavras:

O desempenho de funções precárias e subalternas nas relações de trabalho contemporâneas no Brasil atinge trabalhadoras e trabalhadores periféricos, interseccionalmente oprimidos pela raça e gênero desde a colonização, que continuam silenciados por uma narrativa única de matriz eurocêntrica de celebração da liberdade pelo trabalho subordinado, fruto da colonialidade do saber ainda presente no Direito do Trabalho Brasileiro. (Muradas e Pereira, 2018 p. 2120)

É essa a realidade de um contexto complexo e desigual onde o emprego nunca se tornou a forma majoritária do trabalho. Segundo a Organização Internacional do Trabalho, somente $42,6 \%$ dos trabalhadores nos países em desenvolvimento são empregados, caso da maioria dos países da América Latina (International Labour Office, 2014, p. 40). Assim, a desigualdade antiga e persistente, somada à substituição de postos de trabalho regulados por novas formas laborais precárias (a uberização, p. ex), obriga os trabalhadores a lidarem com riscos prementes da manutenção da vida na ausência ou precariedade da seguridade social, seja essa advinda da cidadania ou do trabalho regulado.

Mas também há resistências e enfrentamentos por dentro do atual sistema socioeconômico. Alejandra León-Cedeño (2006) sugere que as iniciativas igualitárias sejam vistas em três aspectos: como okupação, como resistência e como potência. Esses aspectos tratam da capacidade das pessoas se organizarem para okupar novos espaços de vida em seus territórios, a partir de seus posicionamentos, incidindo sobre eles e produzindo materialidades e socialidades que imaginam ser melhores. Essas ações penetram os "buracos do poder". Para re- 
sistir às dinâmicas de dominação persistentes do cotidiano, a população cria alternativas:

Ampliar os limites do possível sonhando entre todas as possibilidades diferentes das que existem; concretizar mediante as ações de criação coletiva; tecer, ao gerar redes de confiança mútua, uma sociabilidade diferente da que se supõe devemos viver; abrir e ampliar buracos onde seja possível fazer o que bem entendemos. (León-Cedeño, 2006, p. 283)

A emancipação adquire em cada lugar uma forma específica. Peter Spink (2001) argumenta que o lugar é "horizonte de ações e ligações, de produção de sentido e de lutas. O lugar como foi definido em termos práticos, é o lugar da gente" (Spink, 2001, p. 16). As ações que emergem do cotidiano dos diferentes grupos, mais do que projetos formatados a priori, versam sobre aquilo que as pessoas entendem como o melhor e o possível:

Pôr em prática o que coletivamente entendemos como sendo bom naquele lugar e momento, mesmo que não seja legal ou legitimado pela hegemonia. Implica uma coletividade, uma matriz de relações, tensões e conflitos em movimento, buscando okupar espaços de possibilidades intensas e livres. (León-Cedeño, 2006, p. 303)

Assim, o que interessa aqui é a capacidade coletiva de costurar relações de ajuda mútua, planejar e concretizar transformações possíveis no cotidiano, resistindo à racionalidade econômica capitalista e também à precarização do trabalho.

\section{SOBRE O MÉTODO E OS CASOS}

A seguir apresentamos quatro casos que expressam formas distintas de resistência e enfrentamento ao trabalho precário mediante a construção e vivência cotidiana de relações solidárias de trabalho e de vida social, baseadas na cooperação, na ajuda mútua e em vínculos comunitários.

As pesquisas empíricas de onde advém os casos foram realizadas sob o marco teórico-metodológico e epistemológico da Psicologia Social do Trabalho - PST (Sato et al., 2017), o que significou a adoção de uma perspectiva psicossocial crítica para a qual o trabalho é categoria central, necessária à reprodução social das materialidades e das subjetividades; a luta de classe é imprescindível para a explicação dos processos históricos e das relações de poder; e o cotidiano é lugar e tempo onde se vive, se vê a se analisa os indissociáveis processos macro e microssociais. Segundo as autoras:

A crítica tem como alvos a reificação das relações sociais, a exploração do trabalho humano e os limites para uma vida que anseia por fruição, criati- 
vidade e liberdade, não no sentido individualista, característico no neoliberalismo, mas no sentido coletivo e da busca pela cidadania negada no contexto brasileiro atual. (Sato et al, 2017, p. 14)

A adoção do marco da PST implicou em uma opção epistemológica e éticopolítica pela cooperação entre pesquisadores e trabalhadores, nos diferentes casos abordados, na tarefa de produzir conhecimento desde a perspectiva dos trabalhadores sobre suas vidas cotidianas (Freire, 1981). Assim, elas e eles foram tratados como sujeitos conhecedores de sua realidade sociolaboral, o que demandou o estabelecimento de uma relação sujeito-sujeito que visou, intencionalmente, romper com os supostos epistemológicos de submissão e dependência implícitos na relação sujeito-objeto (Fals-Borda, 1985).

Após a exposição dos quatro casos apresentaremos uma metanálise qualitativa (Bicudo, 2014). Trata-se de uma recomposição dos resultados empíricos assumindo um objetivo diferente daqueles das pesquisas originais, a saber, focalizar as relações solidárias de trabalho e de vida social, realizando novas interpretações, realçando elementos diferentes e produzindo uma imagem original.

Os casos comportam diferentes unidades de análise - um bairro, uma cooperativa, um coletivo do MST, duas pessoas criando trabalhos individualmente, em contextos distintos - regiões periféricas de grandes cidades do sul e sudeste do país e no meio rural da região amazônica. A isto se deve a presença de diferentes estilos narrativos dos casos. Eles refletem modos distintos de olhar os fenômenos, já que as situações descritas solicitaram evidenciar diferentes aspectos. A reunião delas aqui assemelha-se a um caleidoscópio que, ao recombinar os resultados empíricos de pesquisas originais, cria uma imagem-síntese nova, e ao mesmo tempo complexa, a respeito das formas de resistência ao trabalho precário no Brasil contemporâneo. Neste sentido, a perspectiva adotada "compreende o mundo do trabalho como algo complexo e que, portanto, precisa também de uma abordagem complexa." (Sato et. al, 2017, p. 18).

\section{OS CASOS}

\section{A Autogestão das Trabalhadoras da Cooperativa Unidas Venceremos (Univens) ${ }^{1}$}

Trata-se de um coletivo autogerido de costureiras de um bairro periférico de Porto Alegre (RS), a Vila Nossa Senhora Aparecida (Instituto Brasileiro de Geografia e Estatística - IBGE, 2018a). Fundada em 1996, a cooperativa permanece em franca atividade até a atualidade (Andrada, 2013; Cordeiro, 2020).

${ }^{1}$ Estudo desenvolvido no Programa de Pós-Graduação em Psicologia Social da Universidade de São Paulo, sob orientação de Leny Sato (Andrada, 2013). 
De início, o grupo era formado apenas por mulheres, trinta e cinco, cujas idades variavam de 18 a 80 anos. A maioria delas era casada e tinha filhos, e teve que interromper os estudos antes de completar o ensino fundamental. À época, a situação de trabalho delas era precária. Muitas faziam, em casa, trabalhos de costura esporádicos e mal remunerados, as facções. Uma delas contou que ganhava o equivalente a um litro de leite por um dia inteiro de trabalho. Eram tempos de Crise do Emprego no Brasil, crise econômica e social, que se estendeu pelos anos 90 e que afetou severamente os setores mais pobres da classe trabalhadora (Singer, 2002; Pochmann, 2001).

A ideia de constituir a Univens surgiu no seio de um pequeno grupo de vizinhas, nas reuniões do Orçamento Participativo (O.P. $)^{2}$, política pública que propiciou uma experiência comunitária importante, responsável por uma profunda transformação do bairro. Muitas delas já se conheciam em razão de experiências anteriores, baseadas em relações solidárias, de ajuda mútua, como a construção da capela e a luta por uma creche comunitária. A Vila surgiu de um movimento de luta por moradia, fruto da ocupação de uma fazenda improdutiva, nos anos 70. Mas havia sido tomado por práticas clientelistas e era repleto de precariedades: esgoto a céu aberto, posto de saúde fechado, ruas escuras, sem nome ou pavimento. A partir da participação de moradores nas reuniões do O.P., o bairro paulatinamente mudou, como também mudaram seus habitantes, sujeitos deste processo.

Por isso, a história da Univens confunde-se com a história da Vila. Ao lutar por elas, os lugares de moradora e cooperada surgem mesclados, formam "um emaranhado", nas palavras da cooperada Terezinha. A imagem parece potente para ilustrar o campo formado por relações solidárias que não se restringem à cooperativa, estendem-se pelo bairro - território que, a seu turno, confere materialidade, história e cotidiano a essas relações, por intermédio de seus agentes: "as pessoas para trabalharem na cooperativa têm que ser da comunidade [...] É um emaranhado, que é pro crescimento em si." (Terezinha, entrevista, março de 2004).

A pesquisa demonstrou que as relações solidárias, alicerces dessa experiência política e comunitária, não apenas são anteriores à cooperativa como foram condições necessárias para a organização dela. Após transformar o território em que vivem e passar por intensa formação política, na prática da democracia participativa no O.P., o grupo voltou-se coletivamente para a condição maltratada que comungavam como trabalhadoras.

2 O Orçamento Participativo é uma política de gestão em que, por meio da democracia participativa, a população decide de forma direta a aplicação de parte dos recursos do orçamento municipal. 
De início, não contaram com qualquer política ou apoio institucional. 0 estatuto da cooperativa levou um ano para ser concluído e foi rejeitado sete vezes pelo órgão jurídico competente. Por falta de alternativas, e em meio a muitas dificuldades, ao longo de sua trajetória, o grupo encontrou forças nas parcerias com movimentos sociais (sindical, eclesial de base etc.). Este fato, somado à falta de políticas públicas adequadas de fomento à Economia Solidária, conferiu ao coletivo um forte apreço por sua autonomia política.

A cooperativa foi legalizada em 1996. Durante quatro anos, teve como sede o salão da capela da Vila, erguida em ação comunitária. Em 1999, mudaram-se para a primeira Incubadora de Cooperativas Populares de Porto Alegre, no mesmo bairro, fruto da luta das trabalhadoras junto ao OP. Em 2005, o coletivo transferiu-se finalmente para a sede própria, outra conquista delas que, ao fundo destinado a este fim, souberam unir o apoio de instituições internacionais ao projeto.

Diante de uma história tão forte de luta pelo direito ao trabalho coletivo digno, pautado por relações solidárias, empenhamo-nos em compreender as motivações das cooperadas em insistir neste projeto, de caráter nitidamente resistente e anti-hegemônico. Notamos que aspectos da dimensão técnica da organização da Univens incidem sobre sua dimensão social de modo a combinar os temas, tempos e espaços das interações cotidianas de acordo com os princípios e necessidades do coletivo. Em outras palavras, as relações solidárias, travadas pelas cooperadas dentro e fora da cooperativa, pautam a organização do trabalho, subordinando-o a elas, e não o contrário. Por exemplo, a Univens adota dois regimes de remuneração. Os setores do corte e da serigrafia têm rotina comum e horários fixos e dividem igualmente a renda. Já as trabalhadoras da costura optaram pela remuneração por peça produzida. Segundo elas, isto possibilita ritmos diferentes de produção e o consequente respeito a idiossincrasias pessoais e familiares.

Há anos o coletivo conta com uma carteira de clientes extensa. A cooperativa fabrica diversos produtos, como sacolas para eventos, uniformes para empresas, escolas e movimentos sociais. Outros produtos relevantes são as camisetas e sacolas para os Fóruns Sociais Mundiais ${ }^{3}$. Nos últimos anos, a Univens experimenta uma estabilidade econômica admirável, gerando renda satisfatória às

\footnotetext{
${ }^{3} \mathrm{Em}$ 2005, as trabalhadoras propuseram que esses produtos fossem fabricados por uma rede de coletivos. Dele participaram 36 grupos de quatro estados. Juntos, cobriram a fiação, a tecelagem e a confecção das sacolas. Processo organizado democraticamente, representou a semente da Justa Trama, uma rede autogerida que reúne 600 trabalhadores/as de cinco coletivos que, juntos, controlam os elos da cadeia do algodão agroecológico. Em pesquisa de doutorado, orientada por Leny Sato, buscamos compreender as relações entre trabalho e política no cotidiano dessa rede (Andrada e Sato, 2014).
} 
trabalhadoras, em patamar superior às empresas capitalistas do setor, marcado pela precarização do trabalho. Mas a conquista dessa estabilidade foi trabalhosa. Requereu tecer outra rede de relações solidárias, densa e extensa, que ultrapassa os limites do coletivo (Andrada e Sato, 2014).

Sentir que o futuro depende umas das outras, solidárias no embate com as circunstâncias, e não de outrem a quem estejam subordinadas, é uma expressão resultante da posse coletiva dos meios de produção que, na cooperativa, pertencem aos/às trabalhadores/as. Junto com a autogestão, são princípios que caracterizam a Economia Solidária, movimento social de resistência ao qual as trabalhadoras pertencem, fundamente analisado por Paul Singer (Andrada e Esteves, 2017). A conquista da autonomia coletiva como condição de trabalho foi uma das repercussões da autogestão mais citadas pelas cooperadas. Com efeito, se não dependem de um patrão, sentem seu futuro atrelado às relações solidárias do grupo e à venda de seus produtos no mercado. Estas, conforme as trabalhadoras, encontram-se diretamente ligadas à qualidade do trabalho que realizam. Nesta ordem de dependência, dizem elas, sentem dispor de mais controle, liberdade e poder de intervenção no trabalho, ainda que sofram com as vicissitudes do mercado capitalista. Elas apontam ainda outro aspecto dessa autonomia especialmente caro às mulheres: a possibilidade de conciliar melhor as demandas da família e do trabalho.

0 processo dialético entre resistir ao sistema dominante e criar um modo autoral de sobreviver a ele parece infindável, nas palavras das trabalhadoras. Mais que o desenlace histórico deste modo de viver o trabalho, de modo geral, é a trama do cotidiano juntas o que importa mais para elas. E, nessa trama, as escolhas que conseguem fazer, ombro a ombro, pelo caminho: "A gente tem que repensar as novas formas de trabalho, que direitos a gente acha que são importantes de serem preservados, que outros vão ter que ser construídos por nós" (Nelsa, entrevista, junho de 2004).

\section{A Coletivização de Terras e Trabalho num Assentamento do MST, na Amazônia ${ }^{4}$}

O avanço das formas capitalistas de produção no campo brasileiro, em especial na Amazônia, teve a expropriação dos/as trabalhadores/as e a violência como principais características (Martins, 1980). Na década de 1970, no auge da ditadura civil-militar, a campanha para atrair os camponeses de todo o país para os estados da região Norte foi intensa e resultou num processo desordenado de

\footnotetext{
${ }^{4}$ Pesquisa realizada no período de 2009 a 2013, sob orientação de Leny Sato, no âmbito do doutorado em Psicologia Social, no Programa de Pós-Graduação em Psicologia Social da Universidade de São Paulo (Nóbrega, 2016).
} 
ocupação das terras amazônicas, inclusive em Rondônia (IBGE, 2018b). Muitos migrantes chegaram crendo na narrativa da terra produtiva e se depararam com condições agrícolas difíceis, cidades com pouca infraestrutura, dificuldade de acesso a serviços de saúde e educação, caracterizando um cenário de precariedade que se agravou ao longo do tempo. Entre os migrantes que conseguiram permanecer em Rondônia, uma parte constituiu formas de organização social coletivas e familiares, vinculadas às pastorais sociais católicas e aos sindicatos de trabalhadores rurais.

Pouco antes da retomada democrática surgiu no Brasil o Movimento dos Trabalhadores Rurais Sem Terra - MST, eclodindo em Rondônia no início da década de 1990 , com as primeiras ocupações de terra naquele período. 0 caso aqui relatado trata da história do "Coletivo 14 de Agosto" que teve início em 1992 quando, às margens da rodovia principal do estado, cerca de 100 famílias ligadas ao MST ocuparam as terras de uma fazenda improdutiva e passaram a construir suas vidas ali.

Passados dois anos da ocupação, vivendo em barracos improvisados sob a "lona preta" (um dos símbolos da luta pela terra do MST), as famílias decidiram organizar seu assentamento naquela terra, uma vez que o Estado nada fazia para assentá-los oficialmente. Em um contexto de ameaças de despejo constantes e, a fim de garantir sua continuidade naquele território que começava a ser construído, as famílias se organizaram, plantando e colhendo alimentos, fazendo funcionar uma escola itinerante para as crianças, entre outras ações. Ainda assim foram violentamente despejados da terra. Ficaram acampados na cidade por meses, e ali se reorganizaram e ocuparam mais uma vez a fazenda, retornando para as terras de onde não saíram mais. Dezessete anos depois, sob muitas ameaças, foram assentados oficialmente pelo Estado brasileiro. Para conquistarem esse direito, a luta pela desapropriação da fazenda passou pela demonstração diária de que aquelas terras seriam produtivas, expressão da conquista da moradia, do trabalho e do alimento. A construção do pertencimento àquelas terras passava por viver bem, trabalhar e produzir alimentos, organizar a luta coletiva e educar as crianças.

Parte das famílias acampadas criou uma agrovila onde as casas ficam próximas umas das outras e constituem, no seu entorno, um centro social. A estratégia do MST era aproximar as moradias para acabar com o tradicional isolamento do camponês (Wanderley, 2003). A arquitetura que desejavam para aquele lugar deveria ser tal que, caso alguém tivesse algum problema, a proximidade favoreceria a resolução do mesmo. Além das casas, construíram na agrovila a sede da escola e uma associação de moradores para, além de fortalecer a luta por 
aquelas terras, também beneficiar e comercializar coletivamente a produção agrícola.

Aos poucos, alguns assentados foram se identificando mais com as práticas cooperativas e, entre os membros da associação, formou-se um grupo interessado em aprofundar a cooperação, e assim iniciaram experiências de coletivização do trabalho agrícola. A orientação do MST era que a cooperação deveria se estabelecer conforme as necessidades e interesses dos núcleos de família dos acampamentos e assentamentos, podendo variar quanto aos formatos de maneira flexível (da cooperação mais complexa aos pequenos experimentos de cooperação). Ao longo do tempo, as famílias interessadas foram testando e alargando a cooperação, construindo no cotidiano socialidades e materialidades que a sustentasse.

Mais do que uma escolha entre muitas, a cooperação se constitui, neste grupo, como uma necessidade, uma questão de sobrevivência diante das condições de vida da população camponesa. Nas primeiras iniciativas de cooperação os homens saíam para trabalhar na roça enquanto as mulheres permaneciam em suas casas para realizar o trabalho doméstico e cuidar das pequenas hortas e animais que ficavam no entorno. As dificuldades econômicas, entretanto, levaram algumas famílias a fazer diariamente suas refeições juntas. Diante da escassez de mão de obra, concluíram que era importante que as mulheres também trabalhassem no roçado e na horta e decidiram "juntar as panelas", tornando coletivo todo o processo de alimentação das famílias envolvidas nas experiências de cooperação agrícola.

Assim foi criada a "cozinha coletiva", um barracão de madeira com um fogão a lenha construído no centro da agrovila, para onde as famílias levaram seus utensílios domésticos e passaram a cozinhar e se alimentar diariamente. Com o tempo, a cozinha, que parecia ser apenas uma forma de resolver problemas práticos da cooperação no dia-a-dia, tornou-se o motor de sustentação de uma experiência de coletivização mais ampla, que passou, inclusive, a questionar a divisão sexual do trabalho que vigora ali, tema em permanente tensão.

Ao mesmo tempo em que o trabalho na produção e parte do trabalho doméstico eram coletivizados, fazia-se necessário coletivizar as terras. Inspirados pelas experiências de coletivização parcial que aconteciam nos assentamentos no país e também nas experiências socialistas conhecidas (especialmente as experiências cubanas) definiram que experimentariam também viver numa única terra, sem divisas de lotes. Mais do que a quantidade de terras de cada um, importava a maneira que trabalhariam nela e as condições objetivas que permitiriam que isso acontecesse. A forma coletiva e autogerida de organizar o trabatho na produção incidiria diretamente sobre o sentido dado à terra. A agroeco- 
logia e as práticas econômicas solidárias foram tomadas como base para a produção agrícola. O trabalho coletivo exigia a terra coletiva e então, em 2003, constituiu-se o "Coletivo 14 de Agosto", que existe até os dias atuais.

Desta experiência depreendemos que a maneira como estas famílias percebem o trabalho na agricultura se transforma a partir da coletivização, alargando-se: o que antes era trabalho para si, torna-se o trabalho para nós. 0 caráter autônomo do uso da terra e a propriedade coletiva dos meios de produção possibilita a construção de socialidades e materialidades coletivas e alternativas organizativas diferentes do modo de trabalhar da família camponesa tradicional. A construção desse cotidiano é marcada pela solidariedade e amizade, pelo sentimento de pertencimento e proteção, por aprender a planejar, decidir e fazer junto e pela convicção de que a coletivização é um tipo de enfrentamento político.

Entre as diferentes implicações das escolhas que o grupo fez ao longo de mais de 20 anos, evidenciou-se a produção de uma territorialidade camponesa combativa e anticapitalista, enraizada em uma história de luta e também numa cosmologia que entende a terra e o trabalho como elementos constitutivos da vida camponesa com sentidos muito distintos da territorialidade do capital. Nesta perspectiva, a terra é herança, é sagrada e é viva; o trabalho é o que se faz para viver bem e a cooperação é uma forma histórica e cotidiana de resistir do campesinato (Candido, 2001). Articulam, no seu fazer cotidiano, política, memória e projeto de sociedade, a partir da autogestão, do trabalho entendido em sua totalidade (produção e reprodução da vida) e da terra como lugar de vida, habitado, povoado.

\section{Conexões da Zona Sul ${ }^{5}$}

Capão Redondo, Campo Limpo, Jardim Ângela e Jardim São Luís são distritos da periferia Sul do município de São Paulo (SP). Eles surgiram da reconfiguração de uma área anteriormente agrícola que se tornou opção de moradia popular ao acompanhar o ciclo de expansão industrial do bairro de Santo Amaro, próximo dali. No auge da política de substituição de importações, entre os anos 1960 e 70, estes bairros receberam uma forte onda migratória de trabalhadores (Dedecca, 2004). Segundo o Censo Populacional de 2010 (IBGE, 2018c), os quatro bairros juntos eram habitados por mais de 1,1 milhão de pessoas, aproximadamente $10 \%$ da população do município de São Paulo.

\footnotetext{
${ }^{5}$ A pesquisa Conexões da Zona Sul foi realizada entre 2015 e 2016, sob supervisão de Peter Spink, como estágio pós-doutoral em Administração Pública na EAESP-FVG.
} 
Segundo Elizabeth Borelli (2012), a rápida expansão dessa periferia está relacionada à procura por moradia em terras com baixo preço, induzindo a autoconstrução de favelas em loteamentos irregulares. Embora cada novo bairro periférico tenha sua própria história, eles estão submetidos às mesmas forças sociais, econômicas e institucionais pois:

É a ilegalidade ou clandestinidade em face de um ordenamento jurídicoinstitucional que, desconhecendo a realidade social desta maioria, nega o acesso aos benefícios urbanos básicos. Configura, deste modo, um processo socioeconômico e político que gera uma concepção de ordem excludente, decretando, com isso, uma condição de subcidadania. (Borelli, 2012, p. 68)

Nesse pedaço da Zona Sul, uma população dotada de recursos escassos construiu sua cidade ao reivindicar serviços e infraestruturas necessárias para a organização do espaço e da vida urbana. A necessidade de moradia digna trouxe consigo a luta por regularização fundiária, arruamento e calçamento das vias, saneamento básico, rede elétrica, transporte coletivo, segurança pública etc. Também ocorreram reivindicações pela instalação dos equipamentos públicos relacionados à cidadania, como escolas, creches e postos de saúde.

Contudo, a abertura comercial de 1990 impôs ao Brasil um lugar subalterno na divisão internacional do trabalho (Pochmann, 2001), acarretando em sua desindustrialização. O fechamento de muitas plantas industriais de Santo Amaro (Dedecca, 2004) fez com que a crise do emprego dos anos 1990 fosse vivida com intensidade redobrada na Zona Sul. Com o desemprego, a violência atingiu um patamar que, em 1994, tornou o Capão Redondo e o Jd. Ângela conhecidos como os bairros mais violentos do mundo (Feiguin e Lima, 1995).

Houve medo, mas houve também reações a ele. Surgiram diversas iniciativas para atrair a juventude sobretudo para a cultura e o esporte. A ação contra a violência conseguiu, em cerca de 20 anos, tornar a Zona Sul um celeiro de produção cultural. Na conjunção entre cultura, solidariedade e trabalho surgiram diferentes coletivos entendidos ali como "empreendimentos culturais solidários". Atrelar cultura, solidariedade, trabalho e renda significa realizar, coletivamente, atividades econômicas a partir da valorização da própria cultura e, com isso, viver a cultura no cotidiano. Como exemplo, um grupo de cabeleireiros/as que valoriza a estética afro-brasileira vive dessa cultura e a recria cotidianamente.

Há coletivos de trabalho, formais ou informais, atuantes em outros segmentos. E também há redes de cooperação. Há empreendimentos que prestam consultoria em agricultura urbana para organizações que possuem espaço para implantação de hortas comunitárias. Tais hortas fornecem produtos para grupos do setor da alimentação que valorizam os sabores das culturas ancestrais. As 
hortas demandam a construção e instalação de cisternas, o que é realizado por coletivos relacionados à ecologia. O mesmo tipo de união ocorre entre os setores da reciclagem e da construção, em que empreendimentos de coleta fornecem entulho para outros que fabricam tijolos. Também há grupos que fazem reformas nas moradias que, por sua vez, são financiadas por bancos comunitários.

As ações desses empreendimentos demandam serviços de artes visuais, comunicação, informatização, contabilidade etc., abrindo espaço para outros coletivos que vão surgindo e se estruturando. Ao mesmo tempo em que aumenta a complexidade das relações econômicas entre empreendimentos solidários, ampliam-se os potenciais de desenvolvimento local, pois trata-se de moradores que trabalham, produzem e consomem na região (Esteves et al., 2019).

\section{Criação Individual de Trabalho e Geração de Rendimento no Mercado Informal $^{6}$}

A busca pela sobrevivência em segmentos pobres da população induz as pessoas a combinarem diferentes formas de trabalho, tanto no mercado formal como no informal. Algumas pessoas criam pequenos trabalhos para gerar rendimento individualmente e para isso as relações solidárias são imprescindíveis. As características do bairro (espaço físico, atividade econômica e segmento social ao qual pertencem os habitantes) são importantes para compreender as possibilidades de construção dessas relações.

Relataremos casos de criação de trabalho de duas mulheres de um bairro da cidade de São Paulo onde residem famílias operárias, de classe média baixa, trabalhadores do setor de serviços, pequenos comerciantes e trabalhadores de ofício (marceneiros, alfaiates, costureiras). Muitos residem em imóvel próprio, havendo famílias que moram no bairro há mais de 60 anos. As habitações são, na maioria, casas térreas e sobrados; há pouco movimento de automóveis; os pedestres que circulam pelas ruas do bairro são, em geral, moradores. As características urbanísticas do bairro facilitam o encontro cotidiano, face-a-face, dos moradores. A convivência pode construir laços de confiança bastante fortes entre vizinhos, a ponto de se emprestar casa para uma vizinha morar, compartilhar linha telefônica ${ }^{7}$ e até mesmo autorizar que a vizinha movimente sua conta bancária.

\footnotetext{
${ }^{6}$ Pesquisa sobre a polimorfia do trabalho. Sato (2017) Diferentes faces do trabalho no contexto urbano.

${ }^{7}$ No Brasil, durante muito tempo, a aquisição de linhas telefônicas fixas foi algo realmente caro.
} 
É nesse bairro que residem Neide e Vera, que criaram trabalhos para gerar rendimento individualmente.

\section{Neide}

A trajetória de trabalho de Neide se iniciou quando jovem e solteira - fora empregada como assistente contábil em empresa de assessoria administrativa. Casada, ela e o marido trabalharam como operários no Japão. Ao retornarem ao Brasil, com os recursos economizados, adquiriram um pequeno comércio que após um breve período foi à falência. Após esse triste episódio, sem conseguir retornar ao mercado formal de trabalho em São Paulo, o marido retornou ao Japão para trabalhar como operário. Neide ficou no Brasil e, aos 50 anos, teve que cuidar de seu neto e de sua mãe, mas precisava complementar o salário do marido. A atividade deveria ser compatível com as exigências de cuidados ${ }^{8}$.

Neide aprendeu uma receita de pão de mel com uma senhora conhecida de sua cunhada que o fabricava em sua casa e o comercializava, informalmente, há muitos anos. Isso possibilitou que essa senhora auferisse rendimento suficiente para criar seus filhos sozinha, custear-lhes o curso superior e melhorasse suas condições de vida.

Para iniciar a fabricação do pão de mel, Neide ganhou equipamentos e instrumentos de colegas, os quais ela não teria condição de adquirir, mesmo sendo baratos. Era na cozinha de sua pequena casa que fabricava os doces. Vida doméstica e vida profissional estavam mescladas no mesmo espaço.

Neide comercializava o produto visitando o domicílio dos moradores do bairro. Além disso, contava com a ajuda de uma colega que tinha um pequeno salão de beleza (em sua residência), onde deixava os doces expostos para serem comercializados para a freguesia do salão. Com a consolidação desse trabalho, tendo construído sua clientela, o sobrinho a ajudou a fazer um cartão de visita a fim de ampliar as vendas. Esse trabalho foi criado e mantido graças a uma rede de ajuda que se ampliava em função do surgimento de novas necessidades. Os rendimentos obtidos com ele eram modestos.

Neide cogitou oferecer seus produtos em pequenas cafeterias, mas, para isso, teria que assegurar condições para produzir regularmente uma quantidade mínima de pão de mel semanalmente, o que não the era possível, pois dispunha de poucas horas para dedicar-se a esse trabalho, uma vez que sua principal atividade era o cuidado da mãe e do neto. Para ela, o trabalho com os doces era uma atividade flexível.

${ }^{8}$ A divisão sexual do trabalho e os encargos e limitações para o trabalho da mulher escapam ao foco deste artigo. 
Para a "criação" desse trabalho, Neide contou com a ajuda de diversas pessoas, em diversos momentos e etapas do trabalho. São ajudas pontuais de uma amiga, de um parente de conhecidos.

\section{Vera}

A trajetória de trabalho de Vera se inicia aos 11 anos e finda aos 70. Batalhadora, sempre trabalhou muito, demonstrando capacidade inventiva admirável e energia infindável. Exceto por um breve período, sempre foi empregada no mercado formal (em empresa privada e, posteriormente, em serviço público). Num determinado período, tendo dois filhos pequenos, com o marido doente e impedido de trabalhar, começou a procurar trabalhos para complementar seu rendimento como assalariada. Desde então, sua trajetória foi marcada pela combinação de emprego e outro trabalho (temporário, bico, voluntário na igreja e cuidado de familiares), além do labor doméstico. Vera fala de seus diversos trabalhos como parte do fluxo natural da vida e deixa claro que todos os trabalhos realizados foram possíveis por pertencer à coletividade do bairro, pois relatando seu percurso para criar trabalho, cita o nome de diversas pessoas que lhe ajudaram.

Dos diversos trabalhos realizados por Vera simultaneamente ao emprego, descreveremos um deles: o de confecção caseira e comercialização de roupas infantis no mercado informal. Ela teve a ideia de iniciar essa atividade, pois ao fazer um trabalho extra (um bico) numa indústria têxtil, soube que ela doava retalhos de tecido. A essa época, Vera era empregada numa indústria de confecção, onde aprendeu a costurar. Frente à possibilidade de ganhar retalhos, sugeriu para Judith (uma colega do emprego) que, com eles, confeccionassem roupas infantis. E assim começaram esse trabalho extra que, após alguns anos, mostrou-se uma importante fonte de rendimento que sustentou sua família quando desempregada. Frise-se que essa ideia foi decorrência da possibilidade de obter os retalhos gratuitamente e de ambas saberem costurar. Vera não tinha máquina de costura e para iniciar a atividade conseguiu uma emprestada de outra colega.

Cada uma construiu seu próprio negócio, mas trabalhavam em cooperação em algumas etapas do processo de trabalho: iam juntas buscar o retalho na fábrica (transportavam grandes volumes de material em ônibus, além de caminharem cerca de $700 \mathrm{~m}$ a pé); resolviam, juntas, problemas técnicos do trabalho de costura e da comercialização das roupas. Essa interação ocorria regularmente, quando discutiam e resolviam conjuntamente os pequenos e grandes problemas, mesmo que afetassem apenas uma delas. Assim, desenvolvia-se o aprendizado contínuo e conjunto. 
Essa forma de cooperação solidária, criada com base na amizade, ocorria mesmo que cada uma delas costurasse em suas respectivas casas. Ambas confeccionavam roupas infantis, entretanto, criavam modelos diferentes e assim foram definindo seus respectivos estilos: Vera fazia modelos mais simples e mais baratos e vendia as roupas para bancas nas feiras livres e Judith confeccionava roupas com modelos mais sofisticados, com mais detalhes, com outros tipos de acabamento e as comercializava para pequenas lojas nos bairros da região. A diferença de estilo era devido à diferença de qualificação de ambas - Judith dominava melhor as técnicas de costura. Deve-se destacar que embora fossem negócios individuais, a relação de ajuda mútua estava presente em vários momentos do trabalho.

\section{Sobre Modos Solidários de Pertencer, Confiar e Resistir}

Aqui apresentamos os resultados da metanálise dos casos relatados (Bicudo, 2014), três advindos de periferias de grandes centros urbanos e uma da área rural, situada entre latifúndios na região amazônica. Os quatro casos mostram táticas (Certeau, 1990) criadas por trabalhadores para resistir à pobreza, à segregação e à vulnerabilidade social produzidas pela economia capitalista mediante formas para resolver os problemas específicos de cada comunidade: violência, desemprego, subemprego, insuficiência de rendimento, dificuldades relacionadas a moradia, poder do latifúndio.

A resistência à precarização se dá mediante relações de ajuda mútua, solidárias (Mauss, 1950) que são sustentadas em vínculos de amizade, de parentesco e de vizinhança. São elas que fornecem o suporte social necessário para a existência, de modo a evitar situações de maior vulnerabilidade social. Tais relações solidárias são constituintes da sociabilidade em determinados segmentos sociais, como evidenciou Antônio Candido (2001) ao falar sobre as transformações no modo de vida caipira.

A pessoalidade que sustenta os vínculos sociais mostrou-se importante para a construção de coletivos organizados de forma autônoma, bem como para que as práticas solidárias sustentem a criação de pequenos trabalhos individuais. Em todos os casos, as relações de confiança foram construídas no decorrer de longos períodos de uma convivência que é facilitada pela proximidade territorial, comunitária e/ou vecinal. Os produtos e serviços oferecidos priorizam atender a determinados mercados (organizações, movimentos sociais, coletivos e moradores do lugar) e adotam, intencionalmente, formas de comercialização que permitem, ao menos parcialmente, reter os recursos econômicos num determinado circuito econômico (Santos, 1979/2004), fortalecendo a comunidade e os sentimentos de pertencimento e de participação. 
O trabalho é fruto das circunstâncias possíveis em função da solidariedade das pessoas e dos recursos disponíveis. A pesquisa empírica mostrou que mesmo quando uma pessoa constrói um "negócio" individual, isso foi possível porque vizinhos, parentes e amigos deram suporte e, de alguma forma, estavam juntos. Sobre os recursos, vê-se que as pessoas criam recriando e, nesse sentido, adotam movimentos táticos (Certeau, 1990), aproveitando-se das oportunidades que se apresentam, pois não dispõem de capital econômico que thes abra maior espectro de possibilidades e escolhas.

Observa-se que o investimento no lugar cria condições para construir estratégias que permitem projetar ações a mais longo prazo por meio do enraizamento e da criação do sentimento de pertencimento àquela comunidade, influenciando nos valores de gerações futuras, como é claramente evidenciado nos casos da Cooperativa Univens, das Conexões da Zona Sul e do Coletivo 14 de Agosto.

A resistência política pode ser sustentada tanto por uma clara orientação anticapitalista, como é o caso da Univens e do Coletivo 14 de Agosto, como pode ser motivada por uma sensibilidade irritável (Thompson, 1993) que define o limite do suportável - caso da criação individual de trabalho e também das Conexões da Zona Sul.

Em todos os casos, as redes sociais compostas por entidades, movimentos sociais, igreja e pessoas mostraram-se importantes para construir e manter as iniciativas criadas. Por sua vez, há iniciativas que tendo se consolidado passam a ter papel na difusão de possibilidades de resistência política nos moldes que seguem. Assim, se essas iniciativas foram forjadas pela necessidade, como também ocorre ao submeter-se ao trabalho subordinado, a experiência de trabalho e de resolução de problemas do lugar mediante formas solidárias pode levar a que trabalhadores consigam desenvolver coletivamente a opção de não mais serem empregados, caso das trabalhadoras da Cooperativa Univens e do Coletivo 14 de Agosto.

A solidariedade é referência para relações horizontais, de compartilhamento e adensamento, e suas formas podem ser bastante elásticas, ela nem sempre é um princípio ou um alvo a ser atingido, mas pode ser condição necessária para viver, pois permite evitar situações de vulnerabilidade.

Por fim, entendemos que a precariedade, no contexto de uma realidade híbrida como a brasileira (Oliveira, 2013), possibilita a geração de "sujeitos organizáveis e organizados" (Julián, 2017) dando nova conotação aos "processos constitutivos de resistências, coleticvidades y mobilización" (Julián, 2017, p. 31) que vão okupando (León-Cedeño, 2006) cotidianamente espaços e produzindo uma racionalidade capaz fazer frente a própria condição de precariedade. 


\section{Considerações Finals - Sobre Pertencimento e Participação}

Nos quatro casos destaca-se a importância dos fenômenos trabalho, comunidade e território, com diferentes centralidades, produzindo solidariedade, identidade e enraizamento. Eles demonstram que o trabalho congrega as pessoas e suas ações, fortalecendo a solidariedade social, que a comunidade amalgama e afirma as identidades sociais, e que o território sustenta o cotidiano de práticas sociais cuja singularidade e possibilidade se dá naquele lugar e produz enraizamento.

Ao nosso ver, a solidariedade advinda do trabalho, a identidade proveniente da comunidade e o enraizamento decorrente do território, em conjunto, produzem o pertencimento e a participação social necessários para resistir e sobreviver ao avanço do capitalismo como modo de produção, como ordenador de regras e criador de valores e de modos de ser.

Embora tais casos tenham origens, propósitos e alcances distintos, a existência deles evidencia a possibilidade da construção de relações sociais solidárias, capazes de produzir e sustentar outra economia e outras subjetividades (antihegemônicas), a depender de cada circunstância, necessidade e intencionalidade.

A primera vista, el mundo parece una multitud de soledades amuchadas, todos contra todos, sálvese quien pueda; pero el sentido común, el sentido comunitario, es un bichito duro de matar. La esperanza todavía tiene quien la espera, alentada por las voces que resuenan desde nuestro origen común y nuestros asombrosos espacios de encuentro. (Galeano, 2009, seção "Cultura \& Espetaculos")

\section{REFERÊNCIAS}

Andrada, Cris F. (2013). Encontro da política com o trabalho: um estudo psicossocial sobre autogestão a partir da experiência das cooperadas da Univens. Otra Economía, 7(12), 45-65. https://doi.org/10.4013/otra.2013.712.03

Andrada, Cris F. \& Esteves, Egeu G. (2017) Sonho, história, loucura? Economia Solidária: um movimento de resistência no mundo do trabalho. In Emerson F. Rasera; Maristela de S. Pereira \& Dolores Galindo (Orgs.), Democracia participativa, estado e laicidade: psicologia social e enfrentamentos em tempos de exceção (pp. 169-187). ABRAPSO.

Andrada, Cris F. \& Sato, Leny (2014). Trabalho e política no cotidiano da autogestão: a rede Justa Trama. Psicologia \& Sociedade, 26(n. spe.), 3-13.

https://doi.org/10.1590/S0102-71822014000500002

Bicudo, Maria A. V. (2014). Meta-análise: seu significado para a pesquisa qualitativa. REVEMAT, 9, 7-20 https://doi.org/10.5007/1981-1322.2014v9nespp7 
Borelli, Elizabeth. (2012). Vulnerabilidades sociais e juvenil nos mananciais da zona sul da cidade de São Paulo. Revista Katálysis, 15(1), 62-69.

https://doi.org/10.1590/S1414-49802012000100006

Candido, Antônio. (2001). Os parceiros do Rio Bonito: estudo sobre o caipira paulista e a transformação dos seus meios de vida. Ed. Duas Cidades, Ed. 34.

Certeau, Michel de (1990). L'invention du quotidien, 1. Arts de faire. Éd. Gallimard.

Coraggio, José L. (1993). La construcción de una economía popular: vía para el desarrollo humano. Instituto Fronesis.

http://www.coraggioeconomia.org/jlc/archivos\%20para\%20descargar/RAZETOART.p $\underline{\mathrm{df}}$

Cordeiro, Betânia S. (2020) Tramas da autogestão: saberes do trabalho associado produzidos na experiência de construção de uma rede de economia solidária autogestionária. Tese Doutorado inédita, Universidade Federal do Rio Grande do Sul. http://hdl.handle.net/10183/219846

Dedecca, Claudio S. (2004). O trabalho na metrópole. In Temás. Szmrecsányi (Ed.), História Econômica de São Paulo (pp. 238-262). Globo.

Esteves, Egeu G.; Pereira, Cleberson da S. \& Spink, Peter K. (2019). Conexões da Zona Sul: mapeamento participativo de atores, ações e relações solidárias. Athenea Digital, 19(1), e2180 https://doi.org/10.5565/rev/athenea.2180

Fals-Borda, Orlando (1985). Conocimiento y Poder Popular: Lecciones con campesinos de Nicaragua, Mexico y Colombia. Siglo XXI.

Feiguin, Dora, \& Lima, Renato S. de (1995). Tempo de violência: medo e insegurança em São Paulo. São Paulo Perspec., 9(2), 73-80

Freire, Paulo (1981). Criando métodos de pesquisa alternativa: aprendendo a fazê-la melhor através da ação. In Carlos R. Brandão (Org.), Pesquisa Participante (pp. 3441). Ed. Brasiliense.

Galeano, Eduardo (2009, 10 de julio). Los mapas del alma no tienen fronteras. Página12, https://www.pagina12.com.ar/diario/suplementos/espectaculos/2-145152009-07-10.html

International Labour Office (2014). World of Work Report 2014: Developing with jobs. ILO. http: //ilo.org/global/research/global-reports/world-of-work/2014/lang-en/index.htm

Instituto Brasileiro de Geografia e Estatística. (2018a). IBGE-Cidades (Porto Alegre). https://cidades.ibge.gov.br/brasil/rs/porto-alegre/panorama

Instituto Brasileiro de Geografia e Estatística. (2018b). IBGE-Cidades (Rondônia). https://cidades.ibge.gov.br/brasil/ro/panorama

Instituto Brasileiro de Geografia e Estatística (2018c). IBGE-Cidades (São Paulo). Instituto Brasileiro de Geografia e Estatística. https://cidades.ibge.gov.br/brasil/sp/saopaulo/panorama

Julián, Dasten (2017). Precariedad laboral en América Latina: contribuciones a un modelo para armar. Rev. Colomb. Soc. , 40(2), 27-46.

http://dx.doi.org/10.15446/rcs.v40n2.66382 
León Cedeño, Alejandra A. (2006). Emancipação no cotidiano: iniciativas igualitárias em sociedades de controle. Tese de doutorado inédita, Pontifícia Universidade Católica de São Paulo. https://tede2.pucsp. br/handle/handle/17162

Martins, José de S. (1980). Expropriação e violência: a questão política no campo. Hucitec.

Mauss, Marcel (1950). Sociologie et Anthropologie. Presses Universitaires de France.

Muradas, Daniela \& Pereira, Flávia S. M. (2018) Decolonialidade do saber e direito do trabalho brasileiro: sujeições interseccionais contemporâneas. Rev. Direito Práx., 9(4), 2117-2142. https://doi.org/10.1590/2179-8966/2018/30370

Nóbrega, Juliana da S. (2016). Terra, trabalho e panelas coletivas: a vida como política no "Coletivo 14 de Agosto", em Rondônia. In Marcelo G. A. Calegare \& Maria I. G. Higuchi (Eds.), Nos interiores da Amazônia: leituras psicossociais (pp. 103-124). CRV.

Oliveira, Francisco de (2013). Crítica à razão dualista: o ornitorrinco. Boitempo.

Pochmann, Márcio (2001). O emprego na globalização: a nova divisão do trabalho e os caminhos que o Brasil escolheu. Boitempo.

Santos, Milton (1979/2004). O espaço dividido: os dois circuitos da economia urbana dos países subdesenvolvidos. Edusp.

Sato, Leny (2012). Feira livre: organização, trabalho e sociabilidade. Edusp.

Sato, Leny (2017). Diferentes faces do trabalho no contexto urbano. In Maria C. Coutinho, Marcia H. Bernardo \& Leny Sato (Orgs.), Psicologia Social do Trabalho (pp. 151171). Vozes.

Sato, Leny; Coutinho, Maria C. \& Bernardo, Marcia H. (2017) A perspectiva da Psicologia Social do Trabalho. In Maria C. Coutinho, Marcia H. Bernardo \& Leny Sato (Orgs.), Psicologia Social do Trabalho (pp. 11-24). Vozes.

Singer, Paul (2002). Introdução à Economia Solidária. Perseu Abramo. https: / / fpabramo.org.br/wp-content/uploads/2018/04/Introducao-economiasolidaria-WEB-1.pdf

Spink, Peter K. (2001). O lugar do lugar na Análise Organizacional. Rev. adm. contemp., 5(spe), 11-34. https://doi.org/10.1590/S1415-65552001000500002

Thompson, Edward P. (1993). Customs in common: studies in traditional popular culture. New Press.

Tilly, Charles (2000). La desigualdad persistente. Manatial.

Wanderley, Maria de N.B. (2003). Agricultura familiar e campesinato: rupturas e continuidade. Estudos Sociedade e Agricultura, 11(2), 42-61. 


\section{LENY SATO}

Psicóloga (USP), mestre em Psicologia Social (PUC-SP) e doutora em Psicologia Social (USP). Professora Titular (Sênior) do Instituto de Psicologia da Universidade de São Paulo (IP-USP).

lenysato@usp.br,

https: // orcid.org/0000-0002-4114-097X

\section{EgEu GÓMEZ EsTEVES}

Psicólogo, mestre e doutor em Psicologia Social (USP). Membro da Associação Brasileira de Pesquisadores da Economia Solidária (ABPES). Coordenador do programa de extensão Universidade Aberta à Economia Solidária (UAES-Unifesp). É professor do Instituto das Cidades da Universidade Federal de São Paulo (Unifesp).

egeu.esteves@unifesp.br

https://orcid.org/0000-0002-2482-4421

\section{CRIS FERNÁNDEZ ANDRADA}

Psicóloga, mestre e doutora em Psicologia Social (USP). Realizou pós-doutorado em Psicologia Social (USP), com apoio da Fundação de Amparo à Pesquisa do Estado de São Paulo (FAPESP) (2015-2018). É professora do Departamento de Psicologia Social da Pontifícia Universidade Católica de São Paulo (PUC-SP).

cris.andrada@gmail.com

https://orcid.org/0000-0002-4939-8924

\section{JULIANA DA SILVA NóBREGA}

Psicóloga (PUC-Campinas), mestre em Psicologia Social (PUC-SP) e doutora em Psicologia Social (USP). Membro do Grupo Amazônico de Estudos e Pesquisas em Psicologia e Educação (GAEPPE). É professora do Departamento de Psicologia da Universidade Federal de Rondônia (UNIR).

juliana.nobrega@unir.br

https://orcid.org/0000-0002-3779-6570

\section{FORMATO DE CITACIÓN}

Sato, Leny; Esteves, Egeu; Andrada, Cris \& Nóbrega, Juliana (2021). Resistências ao trabalho precário por meio de relações solidárias: quatro casos do Brasil. Quaderns de Psicologia, 23(2), e1597. https://doi.org/10.5565/rev/qpsicologia. 1597 


\section{HISTORIA EDITORIAL}

Recibido: 30-12-2019

$1^{a}$ revisión: 06-05-2021

Aceptado: 02-06-2021

Publicado: 31-08-2021 